\title{
Water loss of male and female Alphitobius diaperinus (Coleoptera: Tenebrionidae) maintained under dry conditions
}

\author{
DAVID RENAULT and YANN CORAY
}

UMR 6553 CNRS, Université de Rennes 1, Station biologique, 35380 Paimpont, France; e-mail: renault.david@laposte.net

Keywords. Desiccation resistance, survival, sex, body size, body water, water loss rate, Tenebrionidae, Coleoptera

\begin{abstract}
Survival under dry conditions was examined in males and females of Alphitobius diaperinus Panzer (Coleoptera: Tenebrionidae), a beetle of tropical origin. The range of individual responses and the effect of gender on water loss were also evaluated. Females exhibit significantly longer survival $\left(\mathrm{Lt}_{50}\right.$ and $\left.\mathrm{Lt}_{90}\right)$ than males under desiccating conditions. Larger females beetles have a greater initial water mass and hence can tolerate greater water losses. Such beetles have longer survival under dry conditions. Males and females loose an average of 54.8 and $58.9 \%$ of their body water prior to death. The insects were inactive most of the time, when kept under dry conditions; the rate of decrease in body water was thus reduced. Beetles of both gender display a negative correlation between the rates of water loss under desiccating conditions and the duration of survival. We conclude that the difference in survival period between males and females is due to a combination of greater female tolerance to desiccation and larger body size.
\end{abstract}

\section{INTRODUCTION}

Temperature, food and water availability are the most important parameters that govern an insect's life and its geographical distribution (Chown \& Clarke, 2000; Hochachka \& Somero, 2002). Insects have to keep an adequate body water content in a wide range of environmental conditions (Block, 1996), as desiccation may occur in either cold or warm regions. Under arid conditions, the ability to reduce body water loss is crucial and will govern the survival of insects (Gehrken \& Sømme, 1994). As many desert insects are potentially exposed to long periods without access to water and high temperatures, numerous studies have examined their desiccation resistance. Lower rates of water loss were found in insects from dry habitats than in insects from humid areas (Zachariassen et al., 1988), for example tenebrionid species are generally more resistant to desiccation than other groups of insects (Gehrken \& Sømme, 1994). The mechanisms of reducing and/or tolerating body water loss have been studied in desert Tenebrionidae and Carabidae (e.g. Edney, 1977; Sømme, 1995; Zachariassen \& Pedersen, 2002): the most important routes of water loss being through the cuticle, open spiracles during respiration and faeces (Chown, 2002).

Body size is known to have a considerable effect on desiccation resistance in insects (Chown, 1993; Hadley, 1994). However, despite the fact that sexual size dimorphism is widespread among insect species (Svensson, 1977; Fairbairn, 1997), desiccation resistance has rarely been described in relation to sexual dimorphism (Gibbs \& Markow, 2001). An understanding of the response of individuals with differing characteristics, such as body size, is essential for elucidating the mechanisms of intraand inter-population differences in stress tolerance (Maltby, 1999; Renault et al., 2003a).

The tropical beetle Alphitobius diaperinus (Coleoptera: Tenebrionidae), has been introduced into temperate regions (Howe \& Freeman, 1955) and is generally found in microhabitats characterized by low relative humidity and high food availability (Salin et al., 1999). The critical thermal maximum and the transpiration rate were examined in adults of $A$. diaperinus (Salin et al., 1998, 1999); but no data on the ability of males and females to survive under dry conditions are available. In this study, we examine the range of responses of male and female of Alphito- bius diaperinus maintained under low hydric conditions and then evaluate (i) the duration of survival, (ii) the effect of gender and (iii) the role of body size.

\section{MATERIAL AND METHODS}

\section{Insects}

Adult Alphitobius diaperinus (Panzer) (Coleoptera: Tenebrionidae) were collected from poultry house litter at Carentoir $\left(47^{\circ} 82^{\prime} \mathrm{N}-2^{\circ} 13^{\prime} \mathrm{W}\right)$ (Morbihan, France). The insects were reared for 5 months at $28^{\circ} \mathrm{C}$ in the laboratory and supplied with dry dog food and water ad libitum. Newly hatched larvae were isolated from the cultures and the first generation of emerging adults was used in the experiments. All the insects were between 2 and 3 months-old at the beginning of the experiment.

\section{Desiccation resistance}

To assess the effect of low hydric conditions on survival and water balance of adult $A$. diaperinus, beetles were sampled randomly, placed in individual numbered plastic boxes and maintained in a heated room. The insects were supplied with dry dog food ad libitum. The air temperature and relative humidity (r.h.) of the room were $29 \pm 1{ }^{\circ} \mathrm{C}$ and $5 \pm 1 \%$ r.h. respectively.

\section{Fresh mass, dry mass and water content}

Adults were individually weighed before the beginning of the experiment using a Mettler ${ }^{\circledR}$ micro-balance accurate to $0.01 \mathrm{mg}$ (Initial fresh mass, FMi). Each living insect was weighed daily until its death. The last measure before death corresponded to the final fresh mass (FMf). Dry mass was determined by drying the dead beetles at $60^{\circ} \mathrm{C}$ for 3 days in an air oven followed by 6 days in a desiccator with potassium hydroxide. Maximum tolerance of water loss was estimated by the final water loss expressed as percentage weight loss of dry body mass. Water content (mg/mg dry mass) [(Water mass - Dry mass)/Dry mass] was calculated for each individual. Fresh mass, dry mass and water mass were also measured in untreated beetles (control population, $N=75$ ) sampled randomly. Beetles were sexed by dissection of genitalia (Barke \& Davis, 1967).

\section{Data analysis}

Means are given with the standard deviation (S.D.). Lethal times for $50 \%$ and $90 \%$ of the population $\left(\mathrm{Lt}_{50}\right.$ and $\left.\mathrm{Lt}_{90}\right)$ were 
TABLE 1. The mean (mean \pm S.D.) of initial fresh mass (FMi), final fresh mass (FMf), mass loss (\% of initial fresh mass), initial dry mass (DMi), final dry mass (DMf), initial water mass (WMi), final water mass (WMf), inital water content (WCi) and final water content (WCf) of male and female Alphitobius diaperinus kept under dry conditions (Test insects).

\begin{tabular}{|c|c|c|c|c|}
\hline & \multicolumn{2}{|c|}{ Control insects } & \multicolumn{2}{|c|}{ Test insects } \\
\hline & Males $(n=34)$ & Females $(n=41)$ & Males $(n=17)$ & Females $(n=24)$ \\
\hline FMi (mg) & $13.47 \pm 1.72$ & $17.12 \pm 2.26 * *$ & $14.19 \pm 2.48$ & $16.09 \pm 2.42 *$ \\
\hline FMf (mg) & & & $7.94 \pm 1.57$ & $8.85 \pm 1.19 *$ \\
\hline Mass loss (\% FM) & & & $43.76 \pm 7.62$ & $44.28 \pm 8.72 \mathrm{NS}$ \\
\hline DMi (mg) & $6.47 \pm 1.03$ & $8.25 \pm 1.46 * *$ & $6.86 \pm 1.35$ & $7.68 \pm 1.33 \mathrm{NS}$ \\
\hline DMf (mg) & & & $4.62 \pm 0.76$ & $5.39 \pm 1.16^{* *}$ \\
\hline WMi (mg) & $7.00 \pm 0.88$ & $8.87 \pm 1.26 * *$ & $7.33 \pm 1.13$ & $8.41 \pm 1.08 * *$ \\
\hline WMf (mg) & & & $3.31 \pm 1.30$ & $3.46 \pm 1.20 \mathrm{NS}$ \\
\hline WCi (mg/mg DMi) & $1.09 \pm 0.14$ & $1.09 \pm 0.19 \mathrm{NS}$ & $1.08 \pm 0.50$ & $1.10 \pm 0.51 \mathrm{NS}$ \\
\hline WCf (mg/mg DMf) & & & $0.73 \pm 0.30$ & $0.72 \pm 0.52 \mathrm{NS}$ \\
\hline
\end{tabular}

Mass parameters measured in control insects are also provided. * indicates a value that is significantly different between males and females (NS - non significant, $\left.{ }^{*}-P<0.05, * *-P<0.01\right)$.

determined using a probit analysis. If the fiducial limits of the values did not overlap, the values were significantly different.

Some of the commonly used procedures to remove the effect of body size (Packard \& Boardman, 1987; Read \& Harvey, 1989) were recently criticized (Ranta et al., 1994), and the use of ANCOVA as the correct alternative has been recommended (Garcia-Berthou, 2001). Analysis of covariance (ANCOVA) was carried out to determine the effects of sex and body size on the amount and rate of water loss. Fresh mass was the covariate and sex considered the main effect treatment. Analyses were performed using Minitab ${ }^{\mathrm{TM}}$ software (Minitab Inc, Windows version 13,2000$)$.

\section{RESULTS}

\section{Control population}

Adults of $A$. diaperinus show a sexual size dimorphism: fresh mass and dry mass were significantly higher $(P<0.001)$ in females than in males (Table 1$)$. Water mass also differed significantly between females and males $(P<0.001)$. However, once the effect of body mass was removed, there was no significant difference between the water mass of males and females ( $\mathrm{F}$ $=1.29, P>0.05$ ).

Fresh mass was highly correlated to dry mass in both males and females [males: $\mathrm{DM}=0.5459^{*} \mathrm{FM}-0.8878$ (equation 1 ), $\mathrm{r}$ $=0.91, N=34, P<0.001$; females: $\mathrm{DM}=0.5524 * \mathrm{FM}-1.2068, \mathrm{r}$ $=0.86$ (equation 2 ), $N=41, P<0.001$ ] and to water mass [males: $\mathrm{WM}=0.4541 * \mathrm{FM}+0.8878$ (equation 3 ), $\mathrm{r}=0.88, N=34$, $P<0.001$; females: $\mathrm{DM}=0.4476 * \mathrm{FM}+1.2068$ (equation 4$), \mathrm{r}=$ $0.80, N=41, P<0.001]$.

\section{Desiccation resistance}

\section{Survival}

The duration of survival under low humidity was longer in females: the $\mathrm{Lt}_{50}$ and $\mathrm{Lt}_{90}$ of females (13.89 \pm 0.44 days and $22.77 \pm 0.73$ days $)$ were significantly higher $(P<0.01)$ than in males (11.03 \pm 0.47 days and $17.81 \pm 0.91$ days; Fig. 1$) .100 \%$ mortality occurred on day 30 in females whereas it occurred on day 19 in males.

Importance of sex and body size

Both body water and dry mass are affected during long-term exposure under dry conditions. As it was not possible to determine the dry and water masses of the test beetles at the beginning of the experiment, these values were calculated using the regression determined from the control population (equations 1-4). Water content was also calculated (Table 1).

Fresh mass and water mass declined linearly until death of the insects (data not shown). In females $(N=24)$, a positive correlation was found between the duration of survival and the initial fresh mass, between the duration of survival and the initial water mass, and between the duration of survival and the initial dry mass $(\mathrm{r}=0.57, P<0.01 ; \mathrm{r}=0.57, P<0.01 ; \mathrm{r}=0.58, P<0.01$, respectively), suggesting that females with larger body sizes and higher amounts of body water may survive longer. No such significant correlations were found in males.

ANCOVA analysis with maximum tolerance to water loss ( $\mathrm{LoG}_{10}$ transformed values) as the response variable and both the duration of survival and the initial fresh mass (or the initial water mass) as covariables were performed. Neither the initial fresh mass nor the initial water mass influenced the maximum tolerance to water loss $(P>0.05)$. In contrast, the duration of survival had a significant impact on the maximum tolerance to water and mass losses $(\mathrm{F}=2.07, P<0.05)$, and beetles that were able to tolerate larger water loss had the longer duration of survival $(P<0.05)$.

The fresh mass lost was similar in males and females (ca $44 \%$ ) (Table 1). However, males lost an average of $54.8 \%$ of their body water until death, whereas females lost an average of

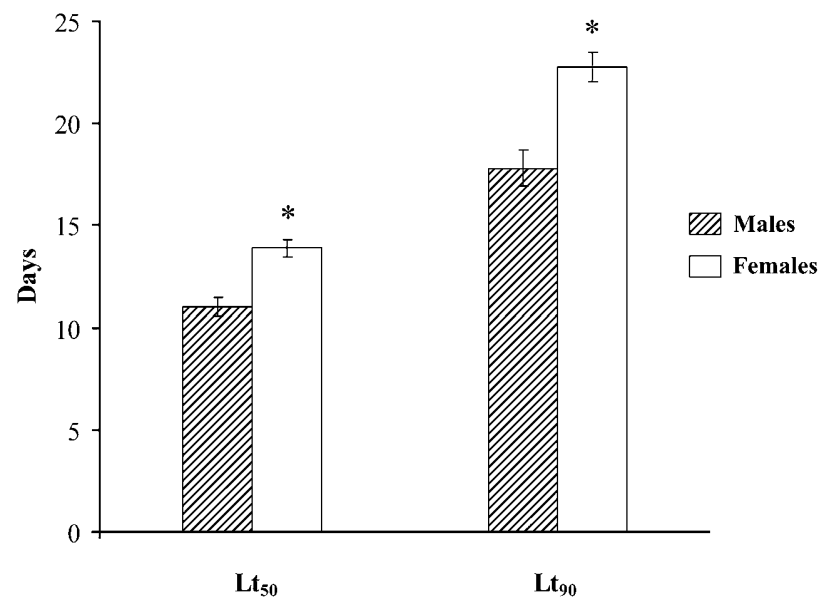

Fig. 1. Survival (mean $\mathrm{Lt}_{50} \pm$ S.D. and mean $\mathrm{Lt}_{90} \pm$ S.D.) of males and females of Alphitobius diaperinus kept under dry conditions. $*$ Indicates a significant difference between males and females $(P<0.01)$. 

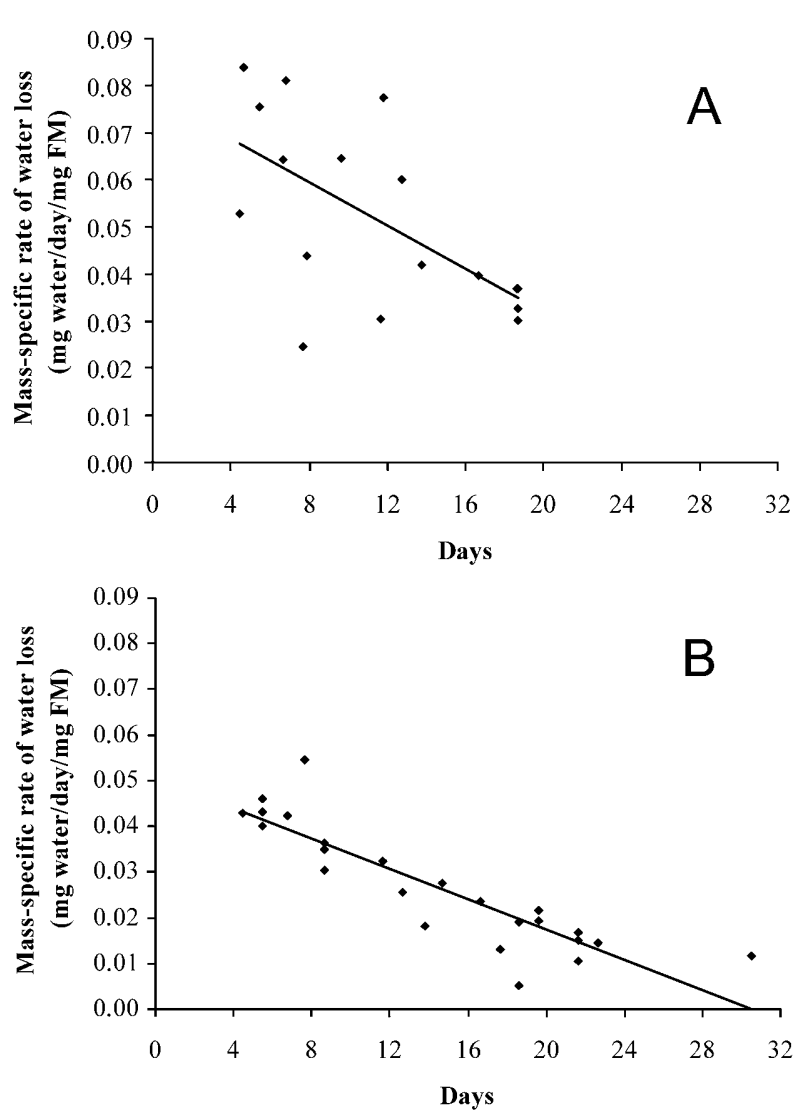

Fig. 2. The relationship between the mass-specific rate of water loss (mg water/day/mg fresh mass) and the duration of survival of beetles kept under dry conditions. A - males $(N=$ $17, \mathrm{r}=0.62, P<0.01)$; $\mathrm{B}$ - females $(N=24, \mathrm{r}=0.88, P<0.001)$.

$58.9 \%$ of their body water $(P>0.05)$. As a result, the highly significant difference found between the water masses of males and females determined at the beginning of the experiment (initial water mass) did not occur at the end of the experiment (final water mass) (Table 1). Final water contents of males and females were similar, but it is noticeable that in each sex a large variability was observed (Table 1).

Once the effects of the duration of survival and body mass were removed, the mean amount of body water loss was similar in males and females $(P>0.05)$. In both sexes, the water mass loss was strongly influenced by the initial fresh mass $(\mathrm{F}=9.68$, $P<0.01$ ). Our results indicate that the mean rates at which body water is lost were similar in males and females kept under dry conditions. In both males and females, a lower rate of water loss (mass-specific basis) enabled a significantly longer duration of survival (Figs 2a and 2b). Moreover, a significant correlation was also found between the rates of body water loss (massspecific basis) and the initial fresh mass (mg). Larger insects exhibited a slower rate of water loss than smaller ones $(P<0.01)$.

\section{DISCUSSION}

\section{Survival under conditions of low humidity}

The mechanisms of desiccation resistance have been studied in detail in desert beetles of the families Carabidae and Tenebrionidae (Hadley, 1994; Sømme, 1995; Zachariassen \& Pedersen, 2002), but differences between sexes have rarely been examined. Females of $A$. diaperinus survive significantly longer under low hydric conditions than males. A higher duration of survival at cold, but non-lethal temperatures, that was found previously in females was likely related to their greater amount of fat reserves (Renault et al., 2003a). Since energetic reserves (triglycerides) were not depleted in starved $A$. diaperinus kept 5 weeks at $24^{\circ} \mathrm{C}$ (Renault et al., 2002), death may, in the present study, rather be caused by the effect of the considerable loss in body water than from the exhaustion of fat reserves.

\section{Importance of sex and body size}

Several behavioural, morphological and physiological adaptations allow insects to survive in dry environments. The abdomen of the tenebrionids, often sphere-shaped and flexible, is generally involved in the storage of a large amount of water (Hadley, 1994; Zachariassen \& Pedersen, 2002), which might be advantageous to extend the duration of survival during dry periods. However, once the effect of body size was removed, no significant differences occurred between the water masses of males and females.

Desiccation resistance is also highly dependent on the ability to tolerate water loss. Males and females lost an average of 54.5 and $58.5 \%$ of their body water respectively, suggesting that females tend to tolerate a slightly higher loss of body water than males. Larger insects (females) may contain larger amounts of lipid reserves (Beenakkers et al., 1985; Pullin, 1987), that may explain why they may tolerate a lower hydration level than males. However, high initial body water and strong ability to tolerate water loss would be useless if the rate at which body water is lost is high.

Rates of water loss show significant variation among individuals: insects that are better able to conserve their water during dry exposures have a longer survival. In both males and females of $A$. diaperinus we found that the mass-specific rate at which water is lost is significantly reduced in larger beetles. Morphological adaptations, such as increased body size, have been found to significantly reduce water loss (Edney, 1977). As the size of an insect increases, there is a proportional decrease in the relative surface area (Hadley, 1994). Hence, an insect of small mass has a larger relative surface area compared with one of large mass and water will be lost through evaporation at a higher rate. The slight, but not significant, slower rate of water loss in females is likely to be related to their larger body size and may contribute to the better survival of females. Moreover, larger insects could tolerate greater water losses than smaller ones because of the higher amount of water that can be lost (Le Lagadec et al., 1998).

Behavioural responses are strongly implied in the reduction of water losses. Insects are subjected to various degrees of desiccation depending on their ability to find moist and sheltered microhabitats (Gehrken \& Sømme, 1994). In this study, the insects were inactive most of the time; this behavioural response is strongly similar to the "sit and wait" strategy described by Renault et al. (2003b) in adults of $A$. diaperinus subjected to starvation. Such inactivity reduces evaporative rates. Salin et al. (1999) previously reported that at temperatures below $40^{\circ} \mathrm{C}$, water loss in inactive beetles of this species is very slight.

\section{CONCLUSION}

The ability to survive under dry conditions is dependent upon several factors that together could greatly increase the duration of survival. We suggest that both increased body size, as a determinant of water content and hence loss that can be tolerated, and reduced rates of water loss, may contribute to differences in dehydration tolerance between sexes. It is also interesting that adult $A$. diaperinus cannot survive on a dry diet, unlike some other insects (Naidu \& Hattingh, 1988; Scholtz \& Caveney, 1988). The utilization of lipid catabolism as a means 
to provide a source of water, as found in keratin beetles (Le Lagadec et al., 1998), may be limited in A. diaperinus.

ACKNOWLEDGEMENTS. We thank P. Vernon and G. Vannier for discussions and helpful suggestions. We are particularly grateful to A.G. Gibbs and D.A. Wharton for commenting on an earlier draft of this manuscript.

\section{REFERENCES}

BARKe H.E. \& Davis R. 1967: Sexual dimorphism in the lesser mealworm, Alphitobius diaperinus (Panz.) (Coleoptera: Tenebrionidae). J. Georgia Entomol. Soc. 2: 119-121.

Beenakkers A.M.T., Van der Horst D.J. \& Van MarrewiJk W.J.A. 1985: Insect lipids and lipoproteins, and their role in physiological processes. Prog. Lipid Res. 24: 19-67.

BLock W. 1996: Cold or drought - the lesser of two evils for terrestrial arthropods? Eur. J. Entomol. 93: 325-339.

Chown S.L. 1993: Desiccation resistance in six sub-Antarctic weevils (Coleoptera: Curculionidae): humidity as an abiotic factor influencing assemblage structure. Funct. Ecol. 7: 318-325.

Chown S.L. 2002: Respiratory water loss in insects. Comp. Biochem. Physiol. (A) 133: 791-804.

Chown S.L. \& Clarke A. 2000: Stress and the geographic distribution of marine and terrestrial animals. In Storey K.B. \& Storey J.M. (eds): Environmental Stressors and Gene Responses. Elsevier Science, Amsterdam, pp. 41-54.

EDNEy E.B. 1977: Water Balance in Land Arthropods. SpringerVerlag, Berlin, Heidelberg, New York, 282 pp.

FAIRBAIRN D.J. 1997: Allometry for sexual size dimorphism: pattern and process in the coevolution of body size in males and females. Annu. Rev. Ecol. Syst. 28: 659-687.

Garcia-Berthou E. 2001: On the misuse of residuals in ecology: testing regression residuals vs. the analysis of covariance. J. Anim. Ecol. 70: 708-711.

Gehrken U. \& Sømme L. 1994: Tolerance of desiccation in beetles from the High Atlas Mountains. Comp. Biochem. Physiol. (A) 109: 913-922.

GibBs A.G. \& Markow T.A. 2001: Effects of age on water balance in Drosophila species. Physiol. Biochem. Zool. 74: 520-530.

Hadley N.F. 1994: Water Relations of Terrestrial Arthropods. Academic Press, San Diego, CA, 356 pp.

Hochachka P.W. \& Somero G.N. 2002: Biochemical Adaptation - Mechanism and Process in Physiological Evolution. Oxford University Press, New York, 466 pp.

Howe R.W. \& FreEman J.A. 1955: Insect infestation of west African produce imported into Britain. Bull. Entomol. Res. 46: $643-668$.

Le Lagadec M.D., Chown S.L. \& Scholtz C.H. 1998: Desiccation resistance and water balance in southern African keratin beetles (Coleoptera, Trogidae): the influence of body size and habitat. J. Comp. Physiol. (B) 168: 112-122.

Maltby L. 1999: Studying stress: the importance of organismlevel responses. Ecol. Appl. 9: 431-440.
Naidu S.G. \& Hattingh J. 1988: Water balance and osmoregulation in Physadesmia globosa, a diurnal tenebrionid beetle from the Namib desert. J. Insect Physiol. 34: 911-917.

Packard G.C. \& Boardman T.J. 1987: The misuse of ratios to scale physiological data that vary allometrically with body size. In Feder M.E., Bennett A.F., Burggren W.W. \& Huey R.B. (eds): New Directions in Ecological Physiology. Cambridge University Press, Cambridge, pp. 216-239.

Pullin A.S. 1987: Adult feeding time, lipid accumulation, and overwintering in Aglais urticae and Inachis io (Lepidoptera: Nymphalidae). J. Zool. Lond. 211: 631-641.

Ranta E., Laurila A. \& Elmberg J. 1994: Reinventing the wheel: analysis of sexual dimorphism in body size. Oikos 70: 313-321.

Read A.F. \& Harvey P.H. 1989: Life history differences among the eutherian radiations. J. Zool. Lond. 219: 329-353.

Renault D., Hervant F. \& Vernon P. 2002: Comparative study of the metabolic responses during food shortage and subsequent recovery at different temperatures in the adult lesser mealworm, Alphitobius diaperinus (Coleoptera: Tenebrionidae). Physiol. Entomol. 27: 291-301.

Renault D., Hance T., Vannier G. \& Vernon P. 2003a: Is body size an influential parameter in determining the duration of survival at low temperatures in Alphitobius diaperinus Panzer (Coleoptera: Tenebrionidae)? J. Zool. Lond. 259: 381-388.

Renault D., Hervant F. \& Vernon P. 2003b: Effect of food shortage and temperature on oxygen consumption in the lesser mealworm, Alphitobius diaperinus (Panzer) (Coleoptera: Tenebrionidae). Physiol. Entomol. 28: 261-267.

Salin C., Vernon P. \& VAnNier G. 1998: The supercooling and high temperature stupor points of the adult lesser mealworm Alphitobius diaperinus (Coleoptera: Tenebrionidae). J. Stored Prod. Res. 34: 385-394.

Salin C., Vernon P. \& Vannier G. 1999: Effects of temperature and humidity on transpiration in adults of the lesser mealworm, Alphitobius diaperinus (Coleoptera: Tenebrionidae). J. Insect Physiol. 45: 907-914.

Scholtz C.H. \& CAVEney S. 1988: Adaptations in trogid carrion beetles to extremely arid conditions. J. Arid Environ. 15: 179-191.

Søмme L. 1995: Invertebrates in Hot and Cold Arid Environments. Springer, Berlin, Heidelberg, New York, 275 pp.

Svensson B. 1977: Life history, energy fluctuations, and sexual differentiation in Ephemera danica (Ephemeroptera), a stream-living mayfly. Oikos 29: 78-86.

Zachariassen K.E., Andersen J., Kamau J.M. \& Maloiy G.M.O. 1988: Water loss in insects from arid and humid habitats in East Africa. Acta Entomol. Bohemoslov. 85: 81-93.

Zachariassen K.E. \& Pedersen S.A. 2002: Volume regulation during dehydration of desert beetles. Comp. Biochem. Physiol. (B) 133: 805-811.

Received August 22, 2003; revised January 23, 2004; accepted April 1, 2004 